\title{
Plant, Human being and Symbiosis
}

\author{
Berov G Lyubomir* \\ Department of Engineer, Independent Innovative Ideas Researcher, Bulgaria
}

*Corresponding author: Berov G Lyubomir, Engineer, Independent Innovative Ideas Researcher, Smolyan 4700, Bulgaria.

To Cite This Article: Berov G Lyubomir. Plant, Human being and Symbiosis. Am J Biomed Sci \& Res. 2019 - 5(1). AJBSR.MS.ID.000863. DOI: 10.34297/AJBSR.2019.05.000863

Received: 此 August 19, 2019; Published: 眥August 29, 2019

\begin{abstract}
Dear reader, in this article I present a unique perspective on how dominant plant species influence the human societies inhabiting their growth areas. I then raise the point that, in order for the human beings to continue increasing our "living space" without disturbing the balance in nature, we must learn to ward off the manipulative influences of other "living creatures", and become the leader, at least within the planet Earth.

Keywords: Plant; Human being; Symbiosis; Earth; Photosynthesis; Anti-humanity
\end{abstract}

\section{Introduction}

Dear reader, have you ever thought about the symbiosis that exists between us, the human beings, and the plants that surround us? In this article, I examine this topic from a very unusual point of view and present several unique perspectives and conclusions that are, I believe, very intriguing. I wonder if you would think similarly after reading this article.

\section{Let's Start by Posing two Questions}

\section{First, what do we mean by the term "Plant world" (the Earth's flora)?}

Most definitions include the trees, bushes, grasses, lianas, ferns and mosses - approximately 300,000 to 315,000 species. Some scientists also classify the marine green algae as a plant. Plants are characterized by their cellulose cell walls and their ability to extract from the sunlight the energy, necessary for their vital processes, through the process of photosynthesis. Plants are a crucial part of life on Earth. They are the major source of oxygen and are an essential element of most ecosystems, especially on land.

\section{The second question is: What is an animal?}

One unusual answer is that animals exist as living organisms thanks to the plants. In order to survive, animals need the chemical energy accumulated in the form of organic compounds that the plants extract from the sunlight during the process of photosynthesis. All animals including us, humans, assimilate this "plant energy" in the process of metabolism, which is the combination of all organic and chemical processes inside of our organisms that are necessary to maintain our lives [1]. Of note, plant products such as grains, fruits and vegetables are the most important elements of our diet.
Dear reader, and now we are ready for the key question of this article: Does the plant world "gift" the animal world (including us), with only the chemical energy we discussed earlier? Or are there other types of known and unknown energies that we receive and absorb in the process? Also, why do plants gift us with energy to begin with? We all know very well that there is no such thing as a free lunch. Now, if you think about it, the real challenge in answering those questions is to accept the possibility that the plants gift us with their energy on purpose. And the challenge, specifically, is to accept the possibility for the plants having intelligence, like ours. And this can't be true, can it? Isn't the intellect a privilege reserved for the human beings only?

I think it's time to give up that perception. Below I present numerous facts that support the thesis that the plants possess intellect and can purposefully alter (even manipulate) our behavior. However, before developing this thesis, let's look at the results of a study conducted by a Team of psychologists at the University of Virginia and their Chinese counterparts. These results are published in Science magazine. The Team have indisputably demonstrated that there are significant differences in the cognitive and psychological behaviors of the inhabitants of North and South China, which are explained by the different cereals grown in these areas.

It is generally believed that the traditional food in China is rice [2-9]. However, in fact this is only true for the provinces located south of the great Yangtze River. The inhabitants of northern China have traditionally grown wheat. The authors of the study assumed that differences in the cereal that people cultivated and consumed have led to distinct difference in their psychology. Those difference, developed over the millennia of Chinese history, persist even today, despite the migration to the cities. 
Psychologists surveyed over 1100 Chinese students who were representatives of Khan's ethnicity and lived in six regions: Beijing (north) and the five provinces of Fujian (southeast), Guangdong (south), Yunnan (southwest), Sichuan (central part) and Liaoning (northeast). The students passed standard tests on holistic thinking (the ability to focus overall, vs. the parts), collectivism, and tendency to nepotism (promoting relatives and friends, regardless of their business skills). The tests showed that the thinking patterns of the Northern Chinese were closer to the Western Europeans, in terms of being more individualistic and thinking analytically. On the contrary, for the Southern Chinese, the team (collective thinking) came first.

For the scientists was extremely interesting to find that Chinese people, living in neighboring regions, but consuming different cereal (rice vs. wheat), had distinctly different psychology, compared to Chinese, living in unconnected regions, but consuming the same cereal. The test results meant that the development of certain cognitive and psychological traits in humans were clearly influenced more by the differences in the type of cereal they cultivated, than the differences in climate or history. Scientists also noted the fact that in the individualistic north of China the number of divorces is greater, than in the south.

Now, let's move on. Based on the above research, I draw a broader set of assumptions that any plant species which dominates a specific geographic area is, in fact, a single, intelligent living organism. That organism is very different from our generally accepted definition of a living organism, but it still obeys the Basic Law of existence that governs the behavior of all living organisms. The Law states that each living creature, as soon as it is born, begins to grow and compete for a larger living space (more resources). And what are the means and tools utilized in this competition? In the way I see it, there are numerous ways to fight that battle resulting in different types of symbiosis.

Let's explore in more detail specifically the symbiosis between plants and humans. Most often it is mutually beneficial and helps both species. However, the assumption we made earlier that a specific plant species dominating a geographic area forms a single intelligent living organism, can help in explaining some unexplained phenomena in the behavior of human societies inhabiting this region. In the scientific experiment conducted in China that we discussed earlier, we already presented the first case where two neighboring human societies were influenced by the "wheat" and "rice" plant organisms to form different behavioral patterns. Unfortunately, this symbiosis is not entirely mutually beneficial, because the behavioral and psychological differences of the neighboring societies likely lead to wars and battles for dominance, and those always result in destruction and casualties.

But here is a much more unambiguous and striking case. It is about the cultivation and processing of the plant species coca. This living creature "coca" is cultivated on huge geographic areas in Latin America. And one of the distinct behavioral peculiarity of the relationships between the people inhabiting the areas where coca is grown and processed, is the manifestation of anti-humanity. To be clear, we are not talking about anti-human behavior in people who use the drug, but, rather, the anti-human behavior in people who grow the plant for sale. The living creature "coca" appears to have aggressive energy which gives the plant an advantage in the fight for space with other plant species. This explains the huge areas that coca has "conquered" over the last 50 years. But going back to our topic - how does the living organism "coca" manipulate people that grow it? I think that, via a mechanism that I cannot explain, the "coca" organism is able to connect with the subconscious level of the minds of some of the people in its areas, and transfer behavioral qualities that lead to manifestations of extreme anti-humanity in the behavior of those people towards everyone they get in contact with. One such manifestations is the formation of huge criminal cartels, with significant economic and military power. Against them there are also powerful state bodies, both across Latin American and the US. As a result, thousands of victims are given on both sides, but the end of this battle is not visible. This is the familiar situation "divide and conquer". I think that to be successful in this fight for resources, we humans must intellectually rise and surpass the intellectual level of the living organisms "plants."

Dear reader, before we conclude, let's review one more interesting case - the human consumption of meat, or the phenomenon called "the meat-eater". You are probably quite surprised - what does eat meat have in common with the topic about plants we have been discussing so far? Keep reading!

According to scientists from the World Climate Council, one of the largest carbon dioxide pollutants in the globe is the production of meat for food. In their opinion, if we want to stop global warming, it is essential to reduce meat consumption dramatically. One steak every two weeks is the maximum that a man can afford in order to not disturb the balance in nature. Now, 2 hectares of land are used for feeding one typical human meat-eater. And, as a result, to feed all meat-eaters on Earth, huge areas globally are dedicated currently to growing feeder crops. Now, in the context of our topic of how plant creatures influence human societies, from the point of view of the feeder plants, in their battle for space, they appear to have been able to manipulate people at a subconscious level so that the majority of people are carnivorous. What would happen if people were to be vegans? The same 2 hectares of land can provide enough food to maintain 80 vegans, which means a lot less living space for feeder crops.

Dear reader, with everything written so far, what I am try to say is: in order for the human beings to continue increasing our living space without disturbing the balance in nature, we must learn to ward off the manipulative influences of other "living creatures", and become the leader, at least within the planet Earth. 


\section{References}

1. Greene Brian (1999) The Elegant Universe.

2. Greene Brian (2004) The Fabric of the Cosmos.

3. Greene Brian (2011) The Hidden Reality.

4. Ceram, C W Gotter (1967) Graber Und Gelehrt.
5. Henrich Joseph (2014) Rice, Psychology, and Jnnovation. 344(6184): 593-594.

6. Bartlett Richard (2009) The Physics of Miracles.

7. Castaneda Carlos (1993) The Art of Dreaming. pp: 1-131.

8. Stephen W Hawking (1973) A Brief History of Time.

9. Lyubomir G Berov (2019) Creating energy field. 19(1): 14069-14070. 